From the Departments of Tumor Immunology, Medical Oncology, Pathology, Radiology, and Dermatology, Radbond University Nijmegen Medical Centre and Nijmegen Centre for Molecular Life Sciences, Nijmegen, the Netherlands.

Submitted November 26, 2004; accepted April 29, 2005.

C.J.A.P and G.J.A. contributed equally to this study.

Authors' disclosures of potential conflicts of interest are found at the end of this article.

Address reprint requests to Gosse J. Adema, PhD, Department of Tumor Immunology, University Medical Center Nijmegen, Geert Grooteplein 26-28, 6500 HB Nijmegen, the Netherlands; e-mail: g.adema@ncmls.ru.nl.

(C) 2005 by American Society of Clinical Oncology

0732-183X/05/2324-5779/\$20.00

DOI: 10.1200/JCO.2005.06.478

\title{
Immunomonitoring Tumor-Specific T Cells in Delayed- Type Hypersensitivity Skin Biopsies After Dendritic Cell Vaccination Correlates With Clinical Outcome
}

I. Jolanda M. de Vries, Monique R. Bernsen, W. Joost Lesterhuis, Nicole M. Scharenborg, Simon P. Strijk, Marie-Jeanne P. Gerritsen, Dirk J. Ruiter, Carl G. Figdor, Cornelis J.A. Punt, and Gosse J. Adema

\section{$\begin{array}{llllllll}\text { A } & \text { B } & S & \mathbf{T} & \mathbf{R} & \mathbf{A} & \mathbf{C} & \mathbf{T}\end{array}$}

\section{Purpose}

Tumor-specific immunomonitoring is essential to evaluate the efficacy of vaccination against cancer. In this study, we investigated the predictive value of the presence or absence of antigen-specific T cells in biopsies from delayed-type hypersensitivity (DTH) sites.

\section{Patients and Methods}

In our ongoing clinical trials, HLA-A2.1+ melanoma patients were vaccinated with mature dendritic cells (DC) pulsed with melanoma-associated peptides (gp100 and tyrosinase) and keyhole limpet hemocyanin.

\section{Results}

After intradermal administration of a DTH challenge with gp100- and tyrosinase peptideloaded DC, essentially all patients showed a positive induration. In clinically responding patients, $T$ cells specific for the antigen preferentially accumulated in the DTH site, as visualized by in situ tetramer staining. Furthermore, significant numbers of functional gp100 and tyrosinase tetramer-positive $T$ cells could be isolated from these DTH biopsies, in accordance with the applied antigen in the DTH challenge. We observed a direct correlation between the presence of DC vaccine-related T cells in the DTH biopsies of stage IV melanoma patients and a positive clinical outcome $(P=.0012)$.

\section{Conclusion}

These findings demonstrate the potency of this novel approach in the monitoring of vaccination studies in cancer patients.

\section{J Clin Oncol 23:5779-5787. (C) 2005 by American Society of Clinical Oncology}

\section{INTRODUCTION}

Dendritic cell (DC) vaccines have been successfully used for the induction of antitumor T-cell reactivity in melanoma patients. ${ }^{1,2}$ These early trials have shown that vaccination with DC is feasible, nontoxic, and effective in some patients, provided that the DC are appropriately matured and activated..$^{3-8}$ To exploit the full potential of these immunostimulatory cells, many questions need to be answered. ${ }^{9}$ These questions can only be properly addressed in clinical trials. Besides clinical end points, it is of utmost importance to monitor the immune reactivity during therapy.

Most immunologic monitoring assays for antigen-specific cytotoxic T lymphocytes (CTL) in peripheral blood in vaccinated patients depended on their ability to proliferate extensively and acquire lytic activity or to release relatively large amounts of cytokines in vitro. ${ }^{10,11}$ The development of fluorescent major histocompatibility complex (MHC)/ peptide tetramers has greatly improved the ability to detect tumor antigen-specific $T$ cells. ${ }^{12}$ This method has proven useful for identifying $\mathrm{T}$-cell responses in peripheral 
blood to peptide-based vaccines. ${ }^{10}$ Additional bioassays, like cytotoxicity assays, or secretion of cytokines, such as interferon gamma (IFN- $\gamma$ ), are essential to measure the functional properties of antigen-specific CTL. ${ }^{13,14}$ Indeed, tetramer-positive $\mathrm{T}$ cells in cancer patients have been described that are functionally ineffective in lysing target cells or producing cytokines. ${ }^{15}$ Therefore, analysis of both frequency and functionality of natural or vaccine-induced CTL is preferred.

Another major question is the optimal compartment in which vaccine-related immune responses should be monitored. Romero et $\mathrm{al}^{16}$ described high numbers of MHC/ peptide tetramer-positive cells in tumor-infiltrated lymph nodes. Unfortunately, lymph nodes and the tumor site itself are not readily available for monitoring purposes. In this study, we tested the hypothesis that skin biopsies taken from delayed-type hypersensitivity (DTH) reactions are an optimal compartment for immunomonitoring purposes.

\section{PATIENTS AND METHODS}

\section{Antibodies, MHC Tetramers, and Immunostaining}

Flow cytometry was performed using fluorescein isothiocyanate-conjugated (anti-HLA class I $[\mathrm{W} 6 / 32]^{17}$ and anti-HLA DR/DP $[Q 5 / 13]^{18}$ ) and phyco erytrin-conjugated monoclonal antibodies (anti-CD80, Becton Dickinson, Mountain View, CA; anti-CD14 and anti-CD83, Beckman Coulter, Mijdrecht, the Netherlands; and anti-CD86, Pharmingen, San Diego, CA). Immunohistochemical analysis was performed with monoclonal antibodies purchased from Pharmingen. Tetrameric MHC-peptide complexes (HLA-A2.1-gp100:154-162, HLA-A2.1-gp100:280-288, HLA-A2.1tyrosinase:369-377, HLA-A2.1-MART-1(ELAGIGILTV), HLAA2.1-HIVgag (SLYNTVATL), and HLA-A2.1-CMV(GLCTLVAML) were provided by H. Spits (Netherlands Cancer Institute, Amster- dam, the Netherlands) or purchased from Immunomics, Beckman Coulter Inc (San Diego, CA).

\section{Patients}

Melanoma patients (stage III and IV according to American Joint Committee on Cancer criteria ${ }^{19}$ ) who are participating in ongoing protocols in which the immune responses of DC vaccines are studied were included. ${ }^{6}$ Eligibility criteria included HLA-A2.1 phenotype, HLA-DR4 phenotype (when also MHC class II binding peptides were used), melanoma expressing gp100 and tyrosinase, and WHO performance status of 0 or 1 . Additional eligibility criteria for stage IV patients included the following: documented progressive disease within 2 months before study entry, serum lactate dehydrogenase $\leq 2 \times$ the upper limit of normal, no prior chemotherapy or immunotherapy within 3 months before study entry, and no residual toxicity from prior treatments. For stage III patients, further eligibility criteria included planned radical lymph node resection and no prior chemotherapy, radiotherapy, or immunotherapy. Patients with brain metastases, serious concomitant disease, or clinical signs of a history of a second malignancy were excluded. The studies were approved by the local regulatory committee, and written informed consent was obtained from all patients.

Patients received the DC vaccine according to different study protocols as listed in Table 1. All patients who remained free of disease progression after the first vaccination cycle were eligible for two maintenance cycles at 6-month intervals, each consisting of three biweekly intranodal vaccinations in a clinically tumor-free lymph node region under ultrasound guidance with mature DC and alternately pulsed with wild-type or modified gp100 and tyrosinase peptides and keyhole limpet hemocyanin (KLH). Nine patients received two maintenance cycles, and 17 patients received one maintenance cycle.

A clinical response was defined as stable disease for more than 4 months or any partial or complete response. Responses were defined according to Response Evaluation Criteria in Solid Tumors. ${ }^{20}$ Toxicity was assessed according to National Cancer Institute Common Toxicity Criteria. Progression-free survival was calculated from the day of the first vaccination. Patients were

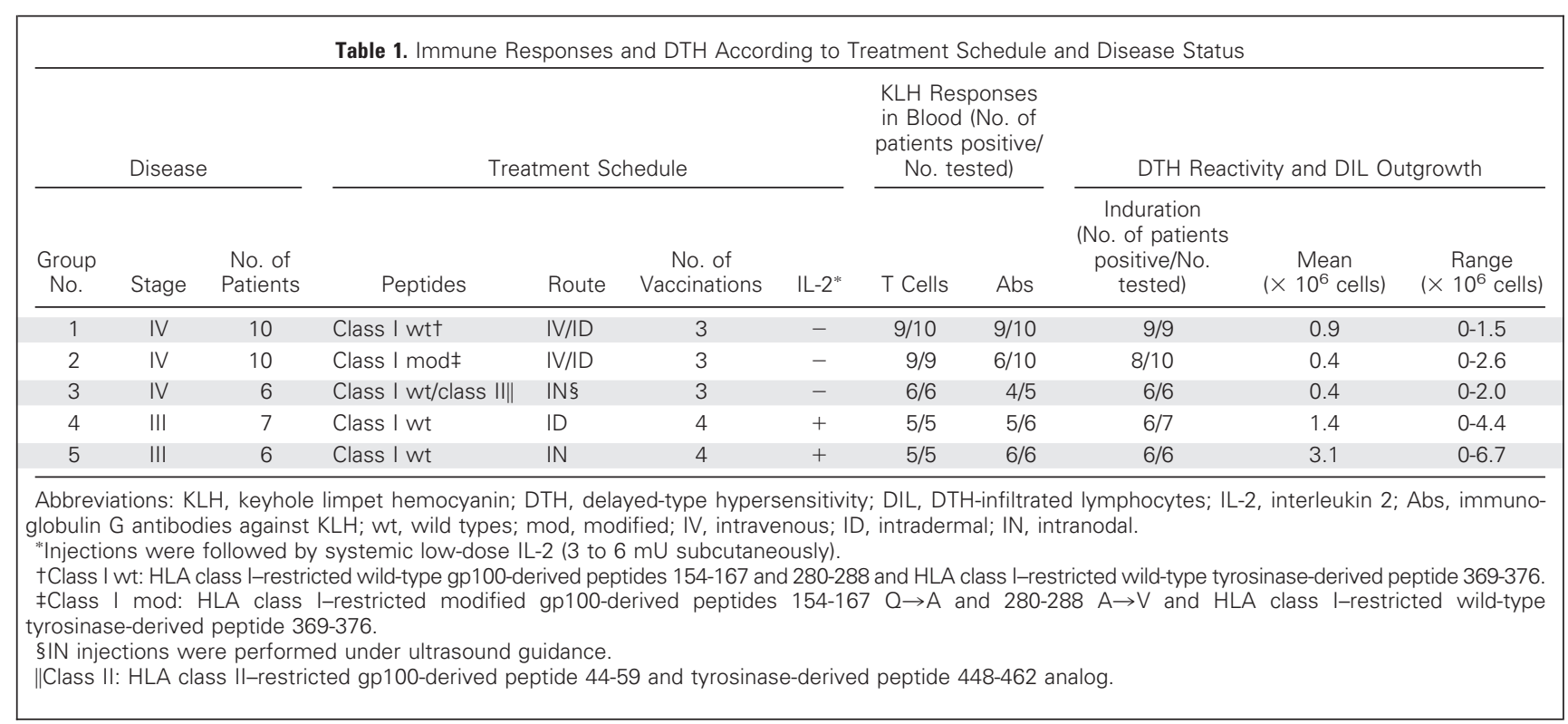


evaluated for response after completing the vaccinations and every 3 months thereafter.

\section{Preparation and Characterization}

KLH-loaded DC were generated from peripheral-blood mononuclear cells (PBMC) and matured with autologous monocyte-conditioned medium with prostaglandin $\mathrm{E}_{2}(10 \mu \mathrm{g} /$ $\mathrm{mL}$; Pharmacia \& Upjohn, Puurs, Belgium) and $10 \mathrm{ng} / \mathrm{mL}$ of recombinant tumor necrosis factor alpha (provided by Dr G. Adolf, Bender Wien, Vienna, Austria), as described previously. ${ }^{21,22}$ This procedure gave rise to mature DC meeting the release criteria described previously. ${ }^{9}$

\section{Peptide Pulsing}

DC were pulsed with the HLA class I gp100-derived peptides gp 100:154-167 (wild type or modified Q $\rightarrow$ A), and gp 100:280-288 (wild type or modified $A \rightarrow V$ ) and the tyrosinase-derived peptide tyrosinase:369-376..$^{23-25}$ DC from HLA-DR4-positive patients were also pulsed with HLA-DR4-binding peptides of both gp100 and tyrosinase (gp100:44-59 and tyro:448-462 analog; both provided by D. Schadendorf, Department of Dermatology, University Hospital Mannheim, Mannheim, Germany). ${ }^{26,27}$ Peptide pulsing was performed as described previously, and cells were resuspended in $0.1 \mathrm{~mL}$ for intradermal (ID) or intranodal injection. ${ }^{6}$

\section{DTH}

One to 2 weeks after a vaccination cycle consisting of three or four DC vaccinations, a DTH skin test was performed. Briefly, unpulsed DC, DC pulsed with the indicated peptides, DC pulsed with $\mathrm{KLH}$, and DC pulsed with the indicated peptides plus KLH (2 to $10 \times 10^{5} \mathrm{DC}$ each) were injected ID in the skin of the back of the patients at four different sites. The maximum diameter of induration was measured after 48 hours.

From positive DTH sites ( $>2 \mathrm{~mm})$, punch biopsies $(6 \mathrm{~mm})$ were obtained and cut in half; one part was cryopreserved, and the other part was cut in pieces. Leukocytes emigrating from these tissue pieces were cultured in RPMI $1640 / 7 \%$ human serum supplemented with interleukin (IL) $-2(100 \mathrm{U} / \mathrm{mL})$. Every 7 days, half of the medium was replaced by fresh IL-2-containing RPMI 1640/7\% HS. After 2 to 4 weeks of culturing, T cells were tested.

\section{In Situ Staining With Tetramer}

From cryopreserved DTH biopsies, 8 - $\mu \mathrm{m}$ thick cryosections were cut. Tissue sections were fixed with $4 \%$ paraformaldehyde ( 3 minutes), and nonspecific protein binding was prevented by using $20 \%$ normal goat serum in phosphate-buffered saline (PBS; 20 minutes). Incubation with tetramer $(5 \mu \mathrm{mol} / \mathrm{L}, 5 \%$ normal goat serum in PBS) was performed overnight at $4^{\circ} \mathrm{C}$ in the absence or presence of CD8 (2 $\mu \mathrm{g} / \mathrm{mL}$, WT82). After washing in PBS, sections were fixed with $4 \%$ paraformaldehyde (20 minutes) and incubated with polyclonal rabbit serum against streptavidine (1:800; Rockland Inc, Gilbertsville, PA). The specific binding of tetramer was visualized using a polyclonal goat-antirabbit-Alexa594 (1:500, 30 minutes, room temperature [RT]; Molecular Probes, Europe BV, Leiden, the Netherlands), resulting in a red fluorescent signal. CD8 was visualized using a polyclonal goat-antimouse-Alexa498 (1:500, 30 minutes, RT; Molecular Probes), resulting in a green fluorescent signal. Sections were counterstained with $4^{\prime}, 6-$ diamidino-2-phenylindole, resulting in blue fluorescent nuclei.

\section{MHC Tetramer Staining}

DTH-derived cells $\left(1 \times 10^{5}\right.$ cells in $\left.10 \mu \mathrm{L}\right)$ or PBMC $\left(1 \times 10^{6}\right.$ cells in $10 \mu \mathrm{L}$ ) were incubated with phyco erytrin-labeled tetrameric-MHC complexes for 1 hour at RT. In the last 20 min- utes of this incubation, fluorescein isothiocyanate-conjugated monoclonal antibodies directed against either CD4 or CD8 (both Becton Dickinson) were added. After washing, the samples were analyzed by flow cytometry.

\section{Cytotoxicity Assay and Cytokine Production}

Cytotoxic activity and production of cytokines by DTHderived cells in response to T2 cells pulsed with the indicated peptides or BLM (a melanoma cell line expressing HLA-A2.1 and no endogenous expression of gp100 and tyrosinase), transfected with control antigen G250, or with gp100 or an allogenic HLAA2.1-positive, gp100-positive, and tyrosinase-positive tumor cell line (MEL624) were measured. Cytotoxic activity of DTHinfiltrated lymphocytes (DIL) was measured using the chromium release assay. ${ }^{28}$ Cytokine production was measured in supernatants after 16 hours of coculture by the cytometric bead array (Th1/Th2 Cytokine CBA 1; BD Pharmingen).

\section{Statistics}

Statistical significance was evaluated using the log-rank test. Statistical analysis was performed with SPSS 11.0 for Windows (SPSS Inc, Chicago, IL).

\section{RESULTS}

\section{DC-Based Vaccination of Melanoma Patients}

In total, 39 melanoma patients were treated with tumor peptide and KLH-loaded DC (Table 1). Most patients mounted a potent proliferative ( 35 of 36 patients tested) and antibody (30 of 37 patients tested) response against KLH (Table 1). The proliferative anti-KLH response was already detected after one DC vaccination (Fig 1). These results demonstrate that the mature DC used were able to mount a de novo immune response.

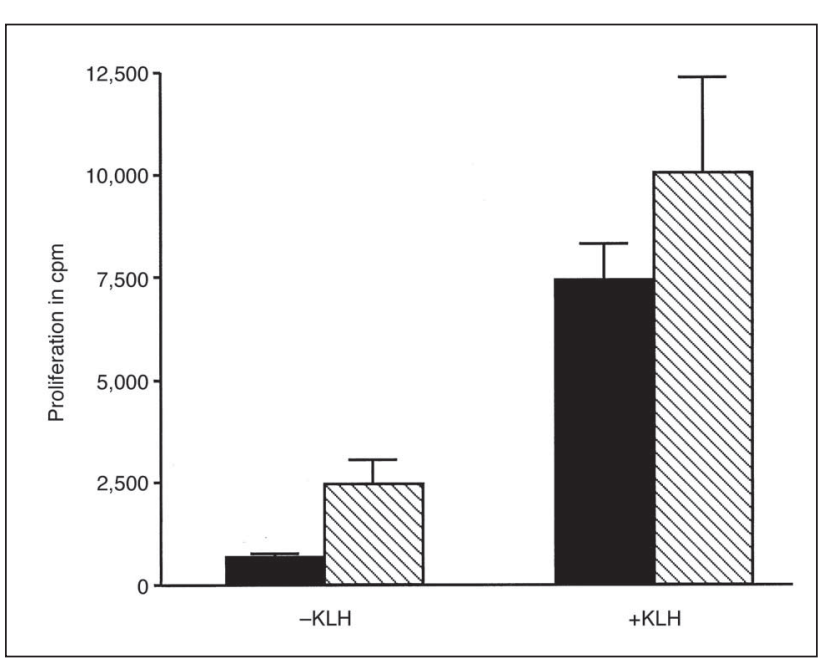

Fig 1. Keyhole limpet hemocyanin (KLH) -specific proliferation of peripheral-blood mononuclear cells (PBMC) and delayed-type hypersensitivity-infiltrated lymphocytes (DIL) after dendritic cell vaccination. Proliferative response against KLH in the PBMC (filled bars) and DIL cultures (hatched bars) of a vaccinated patient (group 1; Table 1) is shown. 


\section{Induration at the DTH Is Not Predictive of a Vaccine-Induced Immune Response}

To investigate the immune response generated in the vaccinated patients, DTH challenges were performed with mature DC. In most patients (35 of 38 patients tested), positive DTH reactions with indurations up to $33 \mathrm{~mm}$ were observed. However, both unloaded DC and DC pulsed with $\mathrm{KLH}$ and/or peptides mounted a positive DTH (Fig 2A). No correlation was observed between the induration size and the type of injected antigen (data not shown). Therefore, in our setting, the induration at the DTH site was not predictive for vaccine-induced immune responses.

\section{DTH: Immunohistochemistry, T-Cell Outgrowth, and Detection of KLH-Specific T Cells}

Infiltrating cell clusters were observed in biopsies taken from DTH sites of peptide- and/or KLH-loaded and -unloaded DC but not in control skin biopsies (Fig 2). The majority of cells $(90 \%)$ in these clusters were $\mathrm{CD} 2^{+}$and $\mathrm{CD}^{+} \mathrm{T}$ lymphocytes (15 biopsies of five patients). Approximately $50 \%$ to $70 \%$ of the cells were $\mathrm{CD}^{+}$, and $30 \%$ to $50 \%$ were $\mathrm{CD}^{+}{ }^{\mathrm{T}}$ cells (Fig 2 ). Only a few $\mathrm{CD} 16^{+}$cells were found scattered between the T-cell clusters, and no $\mathrm{CD} 20^{+}$, $\mathrm{CD}_{23}{ }^{+}$(B lymphocytes), or $\mathrm{CD}^{+} 6^{+}$(natural killer) cells were discerned (data not shown).

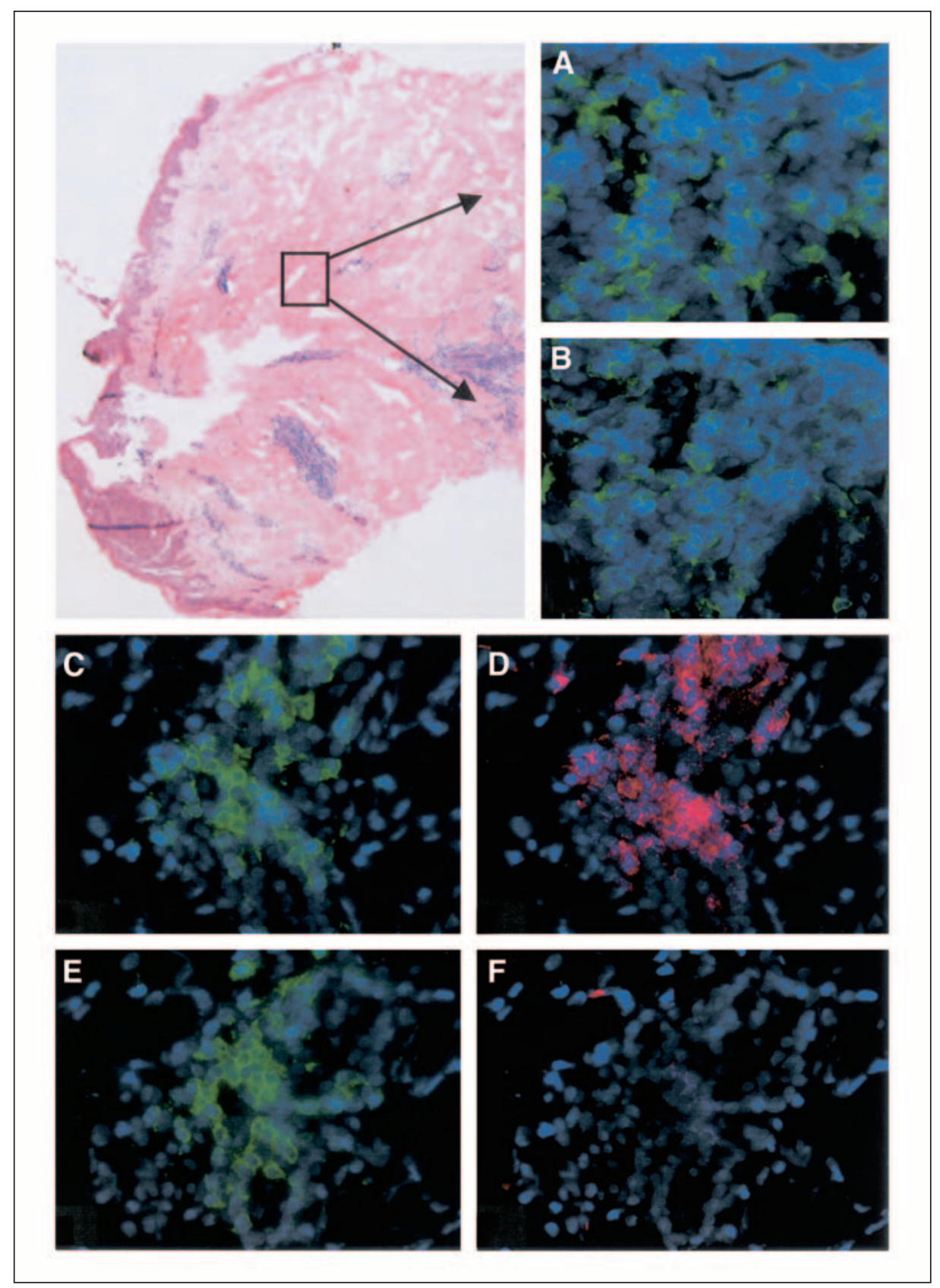

Fig 2. Analyses of delayed-type hypersensitivity (DTH) biopsies in situ. Staining of the DTH sections of a vaccinated patient (group 4; Table 1) revealed infiltrating clusters of (A) CD8 and (B) CD4 T cells. In situ tetramer staining on cryosections of biopsies: sections were stained with CD8 in green $(\mathrm{C}$ and $\mathrm{E})$ in combination with tetramer tyrosinase (D) or gp100:280 (F) in red. Al sections ( $A$ through $F$ ) were counterstained with 4',6-diamidino-2-phenylindole, resulting in blue fluorescent nuclei. 
Leukocytes from DTH biopsies were further characterized after culture with low amounts of IL-2 without the addition of antigen. Outgrowth of DIL occurred in $70 \%$ of the biopsies induced by antigen-loaded DC (32 patients) and in only $55 \%$ of the biopsies induced by unloaded DC. DIL were mainly $\mathrm{T}$ cells, and their amount varied between biopsies ( $\mathrm{Ta}-$ ble 1). The rates of $\mathrm{CD} 4^{+}$and $\mathrm{CD} 8^{+} \mathrm{T}$ cells derived from DIL cultures varied among DIL cultures and between patients $\left(65 \% \pm 21 \% \mathrm{CD}^{+}\right.$and $\left.27 \% \pm 20 \% \mathrm{CD}^{+}\right)$. No correlation was observed between the amount of T-cell outgrowth, the induration, and the presence of KLH. Interestingly, functional analysis of DIL from KLH-pulsed DC demonstrated a KLHspecific response (Fig 1). No anti-KLH response was detected in DIL from a DTH site injected with unpulsed DC (data not shown). Thus, KLH-reactive T cells were specifically detected in DTH sites injected with KLH-loaded DC, and positive induration was not predictive for T-cell reactivity.

\section{DTH: Detection of gp100- and Tyrosinase- Specific T Cells}

To determine the potential of DIL as a source for immunomonitoring of gp 100 - and tyrosinase-specific $\mathrm{CD} 8^{+}$ $\mathrm{T}$ cells, we performed tetramer stainings, the cytokine bead array, or cytotoxicity assays. In 11 (six stage III patients and five stage IV patients) of 22 patients tested, one or more tetramer-positive T-cell population was readily detected after one DC vaccination cycle in biopsies from DTH performed with peptide-loaded DC (Fig 3, Table 2). In five

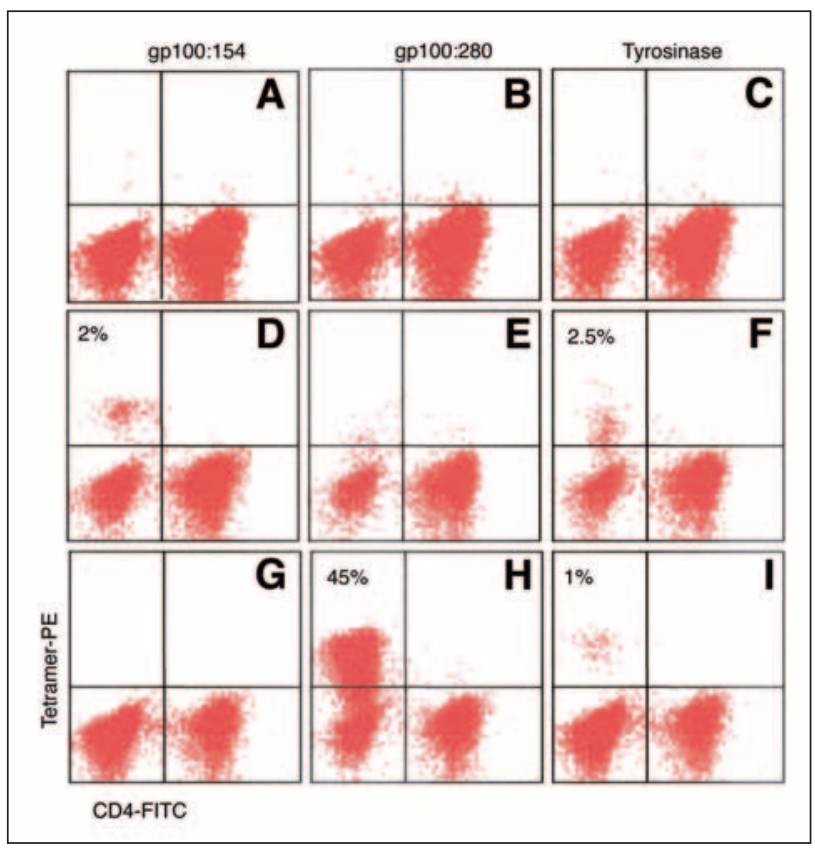

Fig 3. In delayed-type hypersensitivity (DTH) -infiltrated lymphocytes (DIL), dendritic cells $(\mathrm{DC})$ + keyhole limpet hemocyanin $(\mathrm{KLH})$, no tetramerpositive $T$ cells were observed (A to $C$ ). In the same patient (group 4 , see Table 1), positivity for all three tetramers was observed in DTH: DC + three peptides (D to F). In DIL from DTH, DC + KLH + three peptides, positivity for two tetramers were observed (G to I). PE, phyco erytrin.

\begin{tabular}{|c|c|c|c|}
\hline \multirow[b]{2}{*}{ Measure } & \multicolumn{3}{|c|}{ Epitope } \\
\hline & gp100:154 & gp100:280 & tyrosinase:369 \\
\hline \multicolumn{4}{|l|}{ Tetramer } \\
\hline Mean, \%* & 2.6 & 7.3 & 3.3 \\
\hline Range, \% & $0.1-20.0$ & $0.1-45.0$ & $0.6-10.9$ \\
\hline No. positivet & 28 & 11 & 9 \\
\hline \multicolumn{4}{|l|}{$\mathrm{IFN}-\gamma$} \\
\hline Mean, pg/mLł & 3776 & 1,707 & 3,375 \\
\hline Range, pg/mL & $480->10,000$ & $427->5,000$ & $443->10,000$ \\
\hline No. positivet & 16 & 16 & 15 \\
\hline \multicolumn{4}{|c|}{$\begin{array}{l}\text { Abbreviations: DIL, delayed-type hypersensitivity-infiltrated lympho- } \\
\text { cytes; IFN- } \gamma \text {, interferon gamma. } \\
\text { "Mean of the positive tetramer DIL. } \\
\text { †Not all assays performed on every DIL culture } \\
\text { †Mean of IFN- } \gamma \text { production of the positive DIL. }\end{array}$} \\
\hline
\end{tabular}

additional patients, antigen-specific CTL in DIL cultures were detected after additional vaccination cycles (Table 2). No tetramer-positive T cells were detected in DTH biopsies injected with unloaded DC $(\mathrm{n}=4)$ or KLH-loaded DC $(\mathrm{n}=3$; Fig 3). Because significant numbers (up to $45 \%$ of total $\mathrm{T}$ cells) of tetramer-positive $\mathrm{T}$ cells were present in the cultured DTH biopsies (Table 2), we also analyzed the presence of tetramer-positive $\mathrm{T}$ cells directly in blood at the same time point. Strikingly, in six of seven patients, no tetramer-positive cells were found in their PBMC, whereas in five of these six patients, T-cell staining with two different tetramers was readily detected in their DIL cultures. In only one of seven patients, a minor amount of gp 100:154 tetramerpositive $(0.1 \%)$ and tyrosinase:369 tetramer-positive $(0.03 \%)$ $\mathrm{T}$ cells was detected in peripheral blood.

In 15 patients, sufficient DIL were available to determine their cytokine production on coculture with peptide-loaded target cells as well. In nine of 15 patients (27 biopsies), specific cytokine release was detected (Fig 4, Table 2). Moreover, DIL from five patients produced cytokines on coculture with target cells endogenously expressing the tyrosinase or gp100 protein (Fig 4). Especially large amounts of IFN- $\gamma$ and IL-2 were produced, and in some cultures, IL-5, but not IL-4 or IL-10, was detected. Importantly, the observed cytokine production by DIL correlated with the presence and specificity of the tetramer reactivity of the DIL (Fig 3).

Finally, DIL of 23 biopsies from 10 patients were available to determine their cytotoxicity. Six DIL cultures (four patients) efficiently lysed peptide-loaded HLA-A2.1-positive target cells. Again, the observed cytotoxicity corresponded with the presence and specificity of the tetramer reactivity of the DIL (Figs 5A to 5C). Collectively, these data demonstrate that significant numbers of tetramer-positive $\mathrm{T}$ cells accumulated at the DTH site and that these T cells specifically produced cytokines and were cytotoxic for tumor antigen-expressing target cells. 


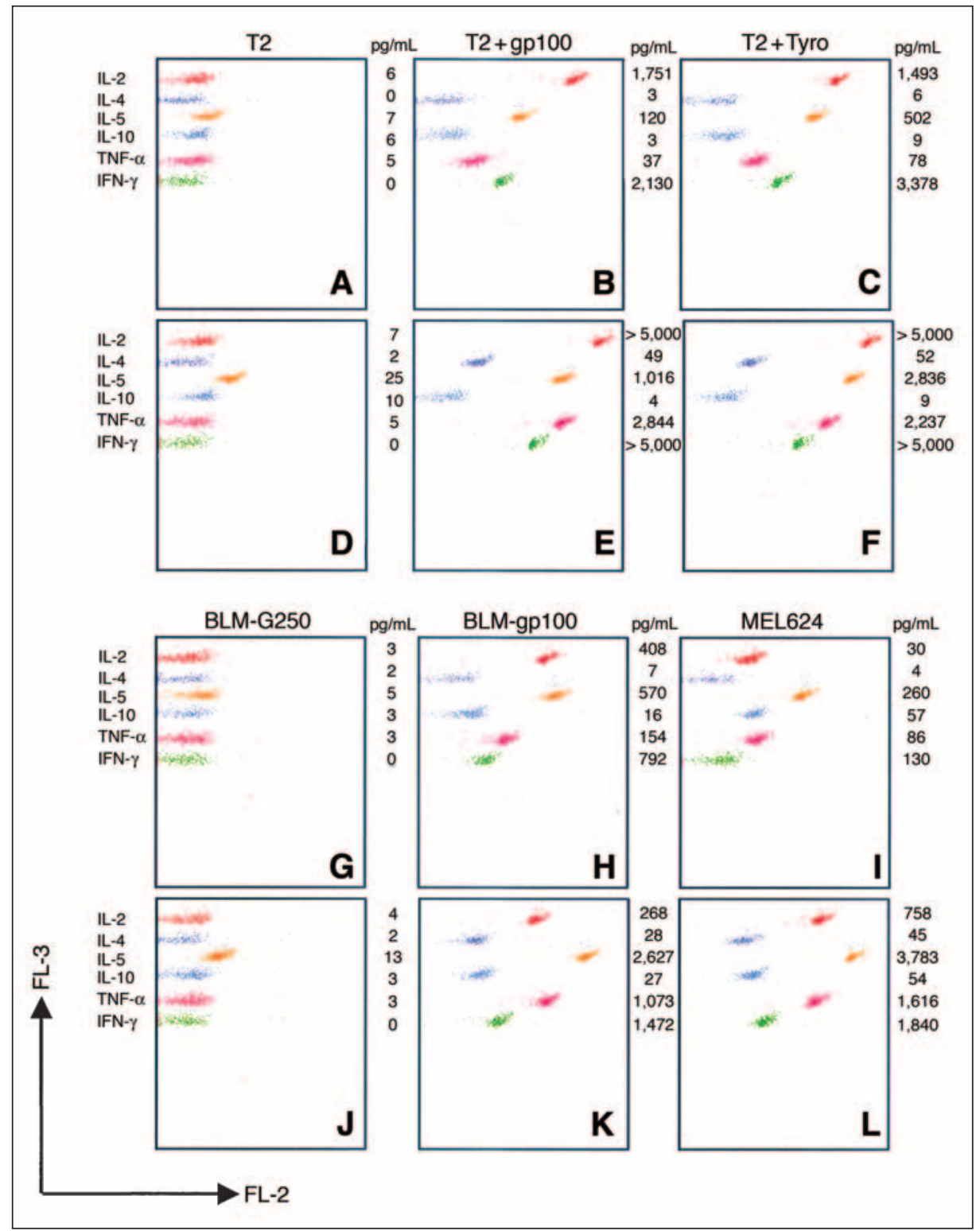

Fig 4. The delayed-type hypersensitivity (DTH) -infiltrated lymphocytes (DIL) of which the tetramer staining is depicted in Figure 3 was also tested for cytokine production. Dendritic cells $(D C)+$ three peptides (A to $C$ and $\mathrm{G}$ to I); DTH: DC loaded + keyhole limpet hemocyanin $(K L H)+$ three peptides ( $D$ to $F$ and $\mathrm{J}$ to $\mathrm{L}$ ). DIL cultures did not recoginze control BLM-G250 (G, J) whereas BLM-gp100 was recognized $(H, K)$. Both DIL cultures recognized MEL624, a melanoma cell line expressing gp100 and tyrosinase (I, L). IL, interleukin; TNF- $\alpha$, tumor necrosis factor alpha; IFN- $\gamma$, interferon gamma.

\section{Detection of gp100- and Tyrosinase-Specific T Cells in Single-Antigen DTH Reactions}

To further discriminate the specific $\mathrm{T}$-cell reactivity in the DTH sites, DTH reactions were induced with mature DC pulsed either with the gp100 peptides or the tyrosinase peptide with or without KLH. Both tetramer and functional analysis demonstrated that the specificity of the accumulated $\mathrm{T}$ cells corresponded with the peptide loaded on the injected DC (Fig 5). DIL derived from gp100 peptide-induced DTH sites (47 tested, 20 positive) were specific for gp100 and did not recognize tyrosinase and vice versa (47 tested, 10 positive). These data provide further support for the hypothesis that $\mathrm{CD} 8^{+} \mathrm{T}$ cells accumulate at DTH sites in accordance with the specificity of the DTH challenge.

\section{In Situ Tetramer Analysis of DTH Biopsies}

We performed in situ tetramer analysis on cryosections of the biopsies to exclude the possibility that the observed $\mathrm{T}$-cell reactivity was induced in vitro. Tetramer-positive cells were clearly detected with the gp100 or tyrosinase tetramers but not with control tetramers (21 biopsies of nine patients). Interestingly, the tetramer-positive cells were specifically present in T-cell clusters (Figs $2 \mathrm{C}$ to $2 \mathrm{~F}$ ), and their specificity fully correlated with the specificity of the peptide loaded on the injected DC. No gp100 or tyrosinase tetramer-positive cells were detected in unloaded $(\mathrm{n}=3)$ and KLH-loaded $(\mathrm{n}=3)$ DTH biopsies. CD8 double staining further demonstrated that most of the tetramer-positive $\mathrm{T}$ cells expressed CD8. 


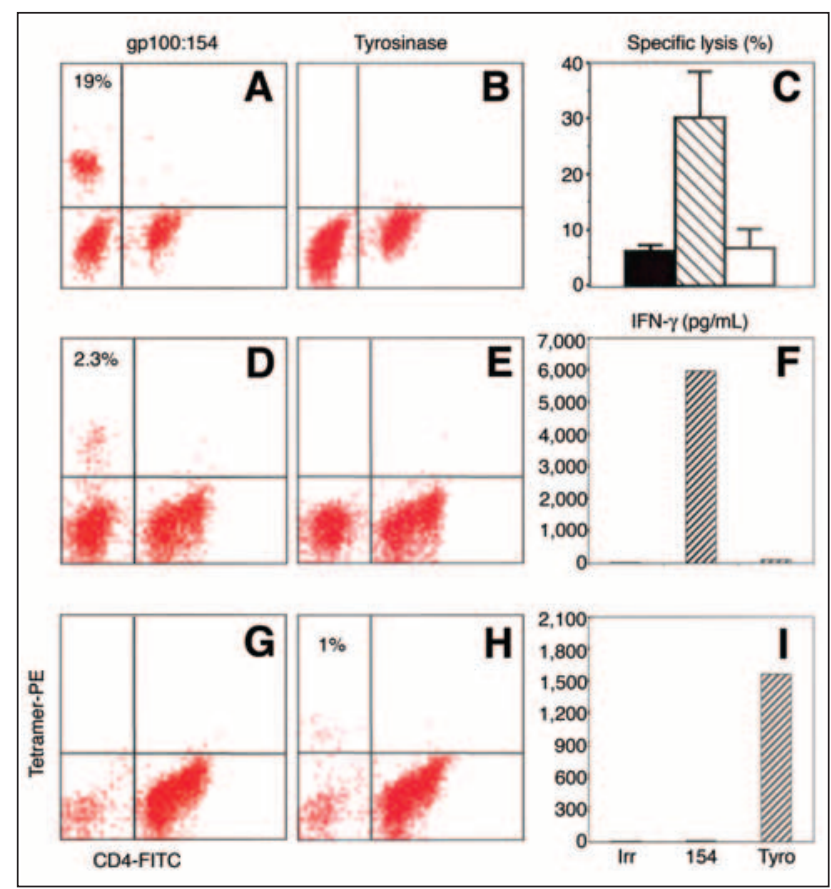

Fig 5. Specificity of the tetramers corresponds with the presense of cytotoxic activity (patient group 5, see Table 1 [C, hatched bar: T2+gp100: 154, open bar: T2+tyrosinase:369, closed bar: T2+irrelevant peptide]) and cytokine production of delayed-type hypersensitivity (DTH) -infiltrated lymphocytes (DIL; F, I). (A to C): DTH: dendritic cells (DC) loaded + keyhole limpet hemocyanin $(\mathrm{KLH})+$ three peptides. In DIL (patient group 4, see Table 1) from DC + KLH + gp100 peptides only T cells positive for gp100 tetramers were observed ( $D$ to $F$ ). Tyrosinase tetramer positivity was observed in the DIL DC + tyrosinase peptide (G to I). IFN- $\gamma$, interferon gamma; PE, phyco erytrin; Irr, irrelevant peptide; Tyro, tyrosinase epitope; FITC, fluorescein isothiocyanate.

In $71 \%$ of the patients exhibiting a positive staining in situ (one half of the biopsy), the specificity correlated with the specificity in the DIL cultures derived from the other half of the biopsy. These findings demonstrate that the antigen-specific $\mathrm{T}$-cell reactivity reflects the in vivo situation and is not artificially induced by in vitro cultures.

\section{Correlation With Clinical Outcome}

To correlate the presence or absence of vaccine-related T-cell responses and clinical outcome, patients were evaluated for clinical response according to Response Evaluation Criteria in Solid Tumors. ${ }^{20}$ Of 26 stage IV melanoma patients, 15 had progressive disease, 10 showed stable disease of at least 4 months in duration, and one patient with multiple liver metastases showed a complete remission. One of the patients with stable disease had salvage surgery and is now disease free at $52+$ months.

No tumor-reactive DIL were observed in 13 of 15 patients with progressive disease (Fig 6). In six of 10 patients with stable disease or better, vaccine-related $\mathrm{T}$-cell responses were observed in their DIL, including one patient with a complete response (Fig 6). The median progressionfree survival time of these six patients was 30 months

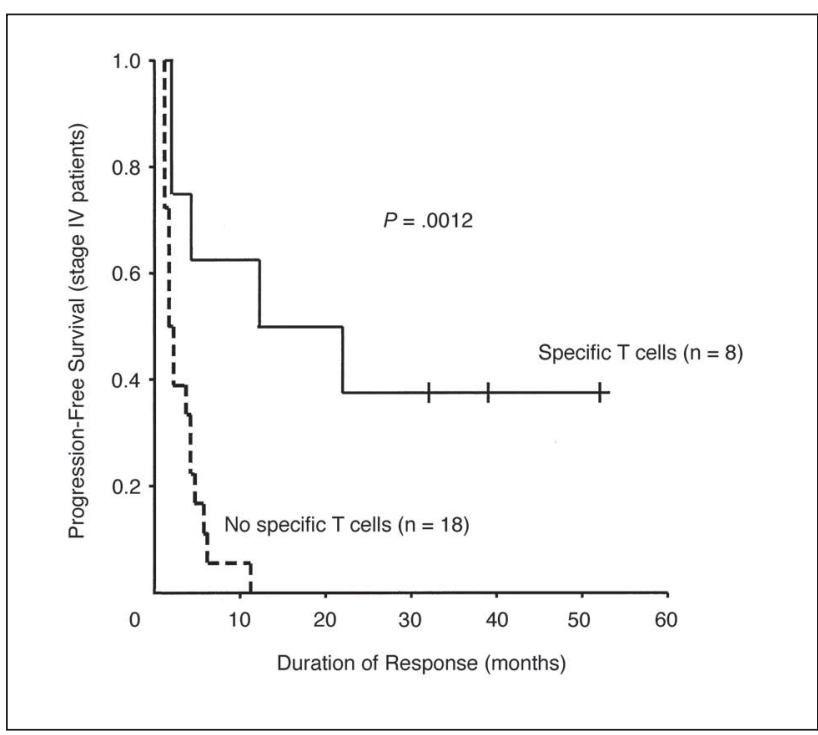

Fig 6. Correlation between the presence of specific $T$ cells and clinical outcome. Kaplan-Meier plot comparing the progression-free survival of stage IV melanoma patients with (closed line) and without (hatched line) tumor-specific T cells in their delayed-type hypersensitivity-infiltrated lymphocytes.

(range, 4 to $52+$ months). For comparison, in the six patients with stable disease without tumor-reactive DIL, the median progression-free survival time was 6 months (range, 4 to 11 months). The median progression-free survival times of stage IV patients with and without tumorreactive DIL were 17 and 2 months, respectively. Although the number of patients was limited, this difference was highly statistically significant $(P=.0012$; Fig 6).

We further noted that, in all stage III melanoma patients tested (10 of 13 patients), a specific T-cell response was readily detected in their DIL. However, because long-term follow-up is required for these patients, no correlation between clinical outcome and the presence or absence of tumor-reactive DIL can be made for this patient group at this time.

\section{DISCUSSION}

Immunomonitoring is an essential step in the development of evidence-based immunotherapy. In this study, we report that sampling of DTH sites is an effective novel approach to detect vaccine-related $\mathrm{T}$ cells predictive for clinical outcome. We demonstrated the following: antigen-specific $\mathrm{T}$ cells specifically accumulated in the DTH and their specificity corresponded with the specificity of the DTH challenge; after a brief culture step, up to $45 \%$ of the $\mathrm{CD}^{+}$cells were antigen specific, produced cytokines, and demonstrated cytotoxic activity towards antigen-positive target cells; and the presence of antigen-specific T cells is predictive for the clinical outcome $(P=.0012)$. 
Prediction of clinical efficacy based on immunologic monitoring is crucial for the rational design of cancer vaccination studies as well as for defining the correlates of protection. Several vaccination studies in cancer patients have reported $\mathrm{T}$-cell responses in the peripheral blood but usually in a minority of patients or only after prolonged re-stimulation with antigen in culture. ${ }^{11,29-32}$ One approach to accumulate $\mathrm{T}$ cells in vivo is to provide a local antigenic challenge by means of a DTH reaction. Measuring the degree of induration on DTH has frequently been used to assess vaccine-related immune responses. In some studies, a correlation with clinical outcome was reported, whereas in other studies, a positive DTH reaction was not predictive for a successful response to vaccination. ${ }^{1,2,33,34}$ In our vaccination settings, the application of a DTH consisting of mature DC with or without antigen induced local indurations and erythema and was not predictive for the presence of vaccine-related T cells. The reason for the DTH response to unloaded DC is not clear but could be explained by the vast amount of chemokines produced by mature DC. ${ }^{22}$ However, this cannot be the sole explanation because patients with a positive DTH reaction after DC vaccination did not develop induration at the site of the first ID injection of up to 25-fold higher numbers of DC.

Antigen-specific T cells were readily detected in the DTH biopsies, whereas at the same time, these $\mathrm{T}$ cells were largely undetectable in blood. Antigenic stimulation of blood lymphocytes at limiting dilution conditions, as described by Coulie et al, ${ }^{11}$ demonstrated that antigen-specific $\mathrm{T}$ cells were detected in blood at low frequencies in our responding patients (range, 1.2 to $7.7 \times 10^{-5}$ of the $\mathrm{CD} 8^{+}$ cells; three patients). Coulie et a $\mathrm{l}^{11}$ also reported low T-cell frequencies in blood and implied that even these low numbers of CTL in blood $\left(5 \times 10^{-5}\right.$ of the total $\mathrm{CD} 8^{+} \mathrm{T}$ cells $)$ correlated with the rejection of a large volume tumor. In our study, the presence or absence of these T cells in the DTH biopsies nicely correlated $(P=.0012)$ with the progressionfree survival of the stage IV melanoma patients. Part of the explanation for this highly significant correlation might be that the conditions to obtain vaccine-specific DIL are more stringent. These specific cells have to migrate and proliferate in vivo, and this might select for high-quality CTL capable of eradicating tumor in vivo. The explanation of why induration at DTH sites per se is not a specific indicator for the induction of vaccine-related responses in many studies, including ours, remains unclear. We note that, after vaccination, but not before vaccination, simply culturing
PBMC in the absence of antigen is sufficient to induce a low level of proliferation in most patients. This finding might indicate that vaccines with potent immune-activating properties, like DC, also induce a certain level of general immune activation sufficient for nonspecific T-cell accumulation, resulting in a positive DTH reaction. Detailed analysis of short-term cultures of DIL generated from biopsies of vaccinated patients revealed that a KLH response was only detected when KLH was used as a challenge, indicating specific accumulation of KLH-reactive T cells. Moreover, gp100/ tyrosinase-specific $\mathrm{CD}^{+}{ }^{+} \mathrm{T}$ cells in the DIL cultures corresponded with the DTH challenge (ie, gp100-specific T cells were only found in biopsies of DTH sites induced by gp100 peptide-loaded DC). No tetramer-positive cells were detected in T-cell cultures derived from DTH sites with unloaded DC or DC loaded with KLH without the peptides. In situ tetramer staining further demonstrated that specific $\mathrm{T}$ cells, corresponding with the DTH challenges, accumulated in vivo and, thus, were not induced in vitro. The DIL cultures containing tetramer-positive CTL were also functionally active because they produced cytokines (predominantly IFN- $\gamma$ ) and induced lysis of cells expressing the appropriate target antigen.

Specific accumulation of antigen-specific $\mathrm{T}$ cells requires the presence of antigen, resulting in specific retention of these T cells. Culturing biopsies from DTH sites unmasks the specific response and, thus, provides a convenient and comprehensive approach to monitor vaccine-related immune responses. Therefore, it will be interesting to apply this approach to other vaccination strategies in which either no correlation or a positive correlation between the degree of induration (as in autologous tumor cell Bacille CalmetteGuerin vaccination) and clinical outcome was observed. ${ }^{33}$ In our recent pilot study, tetramer-specific, IFN- $\gamma$-producing $\mathrm{T}$ cells were also detected after a DTH challenge with peptides alone, thereby obviating the necessity to generate DC in non-DC-based vaccination studies.

Collectively, biopsies from DTH sites after DC vaccination represent a convenient approach to detect antigenspecific T-cell responses that highly correlate with clinical outcome in stage IV melanoma patients. Therefore, this approach may be of great value for the rational design of vaccination studies and development of cancer vaccines.

\section{Authors' Disclosures of Potential Conflicts of Interest}

The authors indicated no potential conflicts of interest.

\section{REFERENCES}

1. Nestle FO, Alijagic S, Gilliet M, et al: Vaccination of melanoma patients with peptideor tumor lysate-pulsed dendritic cells. Nat Med 4:328-332, 1998
2. Thurner B, Haendle I, Roder $C$, et al: Vaccination with mage-3A1 peptide-pulsed mature, monocyte-derived dendritic cells expands specific cytotoxic $T$ cells and induces regression of some metastases in advanced stage IV melanoma. J Exp Med 190:16691678, 1999
3. Schuler-Thurner B, Schultz ES, Berger $T G$, et al: Rapid induction of tumor-specific type $1 \mathrm{~T}$ helper cells in metastatic melanoma patients by vaccination with mature, cryopreserved, peptide-loaded monocyte-derived dendritic cells. J Exp Med 195:1279-1288, 2002 
4. Toes RE, Ossendorp F, Offringa $R$, et al: CD4 $T$ cells and their role in antitumor immune responses. J Exp Med 189:753-756, 1999

5. Melief CJ, Van Der Burg SH, Toes RE, et al: Effective therapeutic anticancer vaccines based on precision guiding of cytolytic T lymphocytes. Immunol Rev 188:177-182, 2002

6. De Vries IJ, Lesterhuis WJ, Scharenborg NM, et al: Maturation of dendritic cells is a prerequisite for inducing immune responses in advanced melanoma patients. Clin Cancer Res 9:5091-5100, 2003

7. Jonuleit $\mathrm{H}$, Giesecke-Tuettenberg A, Tuting $\mathrm{T}$, et al: A comparison of two types of dendritic cell as adjuvants for the induction of melanomaspecific T-cell responses in humans following intranodal injection. Int J Cancer 93:243-251, 2001

8. Dhodapkar MV, Steinman RM, Krasovsky J et al: Antigen-specific inhibition of effector $\mathrm{T}$ cell function in humans after injection of immature dendritic cells. J Exp Med 193:233-238, 2001

9. Figdor CG, de Vries IJ, Lesterhuis WJ, et al: Dendritic cell immunotherapy: Mapping the way. Nat Med 10:475-480, 2004

10. Romero P, Cerottini JC, Waanders GA: Novel methods to monitor antigen-specific cytotoxic T-cell responses in cancer immunotherapy. Mol Med Today 4:305-312, 1998

11. Coulie PG, Karanikas V, Colau D, et al: A monoclonal cytolytic T-lymphocyte response observed in a melanoma patient vaccinated with a tumor-specific antigenic peptide encoded by gene MAGE-3. Proc Natl Acad Sci U S A 98: 10290-10295, 2001

12. Altman JD, Moss PA, Goulder PJ, et al: Phenotypic analysis of antigen-specific $\mathrm{T}$ lymphocytes. Science 274:94-96, 1996

13. Rubio-Godoy $V$, Dutoit $V$, Rimoldi $D$, et al: Discrepancy between ELISPOT IFN-gamma secretion and binding of A2/peptide multimers to TCR reveals interclonal dissociation of CTL effector function from TCR-peptide/MHC complexes half-life. Proc Natl Acad Sci U S A 98:1030210307, 2001

14. Thiel A, Scheffold A, Radbruch A: Antigenspecific cytometry: New tools arrived!. Clin Immunol 111:155-161, 2004
15. Lee PP, Yee C, Savage PA, et al: Characterization of circulating $T$ cells specific for tumorassociated antigens in melanoma patients. Nat Med 5:677-685, 1999

16. Romero $P$, Dunbar PR, Valmori D, et al: Ex vivo staining of metastatic lymph nodes by class I major histocompatibility complex tetramers reveals high numbers of antigen-experienced tumor-specific cytolytic T lymphocytes. J Exp Med 188:1641-1650, 1998

17. Barnstable CJ, Bodmer WF, Brown G, et al: Production of monoclonal antibodies to group A erythrocytes, HLA and other human cell surface antigens: New tools for genetic analysis Cell 14:9-20, 1978

18. Quaranta V, Walker LE, Pellegrino MA, et al: Purification of immunologically functional subsets of human la-like antigens on a monoclonal antibody (05/13) immunoadsorbent. J Immunol 125:1421-1425, 1980

19. Balch CM, Cascinelli N: The new melanoma staging system. Tumori 87:S64-S68, 2001

20. Therasse $P$, Arbuck SG, Eisenhauer EA, et al: New guidelines to evaluate the response to treatment in solid tumors: European Organization for Research and Treatment of Cancer, National Cancer Institute of the United States, National Cancer Institute of Canada. J Natl Cancer Inst 92:205-216, 2000

21. Thurner B, Roder C, Dieckmann D, et al: Generation of large numbers of fully mature and stable dendritic cells from leukapheresis products for clinical application. J Immunol Methods 223:1-15, 1999

22. De Vries IJ, Eggert AA, Scharenborg NM, et al: Phenotypical and functional characterization of clinical grade dendritic cells. J Immunother 25:429-438, 2002

23. Bakker AB, Schreurs MW, Tafazzul G, et al: Identification of a novel peptide derived from the melanocyte-specific gp100 antigen as the dominant epitope recognized by an HLA-A2.1 restricted anti-melanoma CTL line. Int J Cancer 62:97-102, 1995

24. Wolfel T, Schneider J, Meyer Zum Buschenfelde $\mathrm{KH}$, et al: Isolation of naturally processed peptides recognized by cytolytic T lymphocytes (CTL) on human melanoma cells in asso- ciation with HLA-A2.1. Int J Cancer 57:413-418, 1994

25. Cox AL, Skipper J, Chen Y, et al: Identification of a peptide recognized by five melanomaspecific human cytotoxic $T$ cell lines. Science 264:716-719, 1994

26. Topalian SL, Gonzales MI, Parkhurst M, et al: Melanoma-specific CD4+ T cells recognize nonmutated HLA-DR-restricted tyrosinase epitopes. J Exp Med 183:1965-1971, 1996

27. Li K, Adibzadeh M, Halder T, et al: Tumourspecific MHC-class-II-restricted responses after in vitro sensitization to synthetic peptides corresponding to gp100 and Annexin II eluted from melanoma cells. Cancer Immunol Immunother 47:32-38, 1998

28. Bakker AB, Schreurs MW, de Boer AJ, et al: Melanocyte lineage-specific antigen gp100 is recognized by melanoma-derived tumor-infiltrating lymphocytes. J Exp Med 179:1005-1009, 1994

29. Brossart P, Wirths S, Stuhler G, et al: Induction of cytotoxic T-lymphocyte responses in vivo after vaccinations with peptide-pulsed dendritic cells. Blood 96:3102-3108, 2000

30. Lau R, Wang F, Jeffery G, et al: Phase I trial of intravenous peptide-pulsed dendritic cells in patients with metastatic melanoma. J Immunother 24:66-78, 2001

31. Valmori $D$, Dutoit $V$, Schnuriger $V$, et al: Vaccination with a Melan-A peptide selects an oligoclonal $\mathrm{T}$ cell population with increased functional avidity and tumor reactivity. J Immuno 168:4231-4240, 2002

32. Speiser $D E$, Lienard $D$, Pittet $M J$, et al: In vivo activation of melanoma-specific CD8(+) T cells by endogenous tumor antigen and peptide vaccines: A comparison to virus-specific T cells Eur J Immunol 32:731-741, 2002

33. Vermorken JB, Claessen AM, van Tinteren $\mathrm{H}$, et al: Active specific immunotherapy for stage II and stage III human colon cancer: A randomised trial. Lancet 353:345-350, 1999

34. Hersey P, Menzies SW, Halliday GM, et al: Phase I/II study of treatment with dendritic cel vaccines in patients with disseminated melanoma. Cancer Immunol Immunother 53:125134, 2004 